\title{
TERAPIA FAMILIAR SISTÊMICA E IDOSOS: CONTRIBUIÇŌES E DESAFIOS
}

\author{
Maria Clara P. de Paula Couto* \\ Laissa Eschiletti Prati** \\ Deusivania Vieira da Silva Falcão*** \\ Silvia Helena Koller****
}

\section{RESUMO}

O presente artigo descreve algumas intervenções clínicas de orientação sistêmica que podem ser realizadas com a população idosa. Quatro modalidades terapêuticas são abordadas: a terapia individual com idosos, a terapia de casal na terceira idade, o atendimento familiar com membros idosos e o idoso percebido como recurso à terapia familiar. Partindo de alguns conceitos desenvolvidos pela literatura da área, descrevemos situações prototípicas vivenciadas na terapia sistêmica com os desafios específicos desse momento de ciclo vital. O idoso pode ser percebido como um peso/fardo ou como um recurso pelo sistema familiar ao qual pertence, e até por ele mesmo. Por outro lado, a velhice bemsucedida reflete um posicionamento pessoal que é intimamente influenciado pelas relações no sistema familiar dos idosos.

Palavras-chave: idoso; terapia familiar; qualidade de vida; recursos; velhice

\section{AbSTRaCT}

SYSTEMIC FAMILY THERAPY AND THE ELDERLY: CONTRIBUTIONS AND CHALLENGES

This study aims to describe some systemic clinical interventions focused on the treatment of elderly individuals. Four different therapeutics modes are explored: individual therapy, couple's therapy, family therapy with elder family members, and accessing elder members to help in the

* Universidade Federal do Rio Grande do Sul (UFRGS).

** Universidade Federal do Rio Grande do Sul (UFRGS).

*** Universidade de São Paulo (USP).

**** Universidade Federal do Rio Grande do Sul (UFRGS). 
family therapy process. Some prototype situations in therapy with elderly individuals are discussed, taking into account some concepts developed in family therapy. The elderly can be perceived by the family, or even by themselves, as a weight or as a resource. On the other hand, successful aging reflects a personal position that is influenced by family relations.

Keywords: elderly; family therapy; quality of life; resources; aging

O aumento da população idosa é uma realidade com a qual muitos países têm se deparado. Novos desafios surgem para a sociedade e para os pesquisadores e planejadores de políticas sociais em decorrência do aumento da longevidade. É fundamental que esses profissionais se comprometam com projetos que busquem a geração de boas condições de vida para as pessoas dessa faixa etária. As capacidades e possibilidades de desenvolvimento e crescimento na velhice devem ser reconhecidas e estimuladas para que o indivíduo possa envelhecer de forma plena e bem-sucedida. Assim, o presente artigo centraliza-se na última fase do ciclo vital, propondo reflexôes e sugestôes sobre intervençôes terapêuticas em sistemas familiares com idosos.

Nas sociedades ocidentais, ainda prevalece a idéia de que a velhice é um período de doenças, de perdas e de solidão. $\mathrm{O}$ idoso pode ser percebido como um peso, fardo ou como um recurso pelo sistema familiar ao qual pertence, e até por ele mesmo. Entretanto, é importante que, além do reconhecimento dos possíveis riscos característicos dessa fase da vida, suas possibilidades de crescimento não sejam negligenciadas (Paula Couto, Koller \& Novo, 2006). Portanto, no processo de envelhecimento, como em outros momentos do ciclo evolutivo, adversidades podem estar presentes. O desafio encontra-se em manter e renovar a vida de maneira significativa e produtiva. Os idosos são desafiados a compensar possíveis perdas aprendendo novas possibilidades, reforçando e valorizando as áreas que se mantêm e as novas habilidades desenvolvidas (Knopoff, Santagostino \& Zarebski, 2004).

Pesquisadores vêm deslocando a atenção, outrora dada à patologia, a uma posição mais positiva, que se dedica ao estudo dos recursos e das potencialidades existentes na velhice (Paula Couto e cols., 2006; Seligman \& Csikszentmihalyi, 2000). Deste modo, as abordagens teórico-clínicas atuais vêm salientando que o processo de envelhecimento não se compõe apenas de perdas e limitações, e que cabe aos terapeutas explorarem essas questóes junto aos pacientes idosos e seus familiares. A autonomia adquirida pelos idosos, na sociedade atual, gera um novo campo de amizades e investimentos sociais que criam uma nova atmosfera e possibilidades de vivência da velhice. Entre estas novas possibilidades encontra-se o 
desenvolvimento de uma área de estudo e prática psicológica específica para esse momento do ciclo evolutivo, denominada psicogerontologia. O processo terapêutico nessa faixa etária possui características específicas, ainda pouco estudadas. Em função disso, apresentam-se, neste estudo, quatro exemplos de diferentes modalidades terapêuticas nas quais os idosos podem se inserir e, também, alguns aspectos relevantes no desenvolvimento do sistema terapêutico característico com pessoas nessa faixa etária.

A terapia familiar foi desenvolvida por um grupo heterogêneo de estudiosos que trabalhavam em contextos diferentes e com propósitos diversos. Nesse prisma, há várias terapias de família e cada uma possui maneiras distintas de conceituar e tratar as famílias. Todavia, é crucial refletir que a influência conceitual mais importante para esse campo foi a Teoria Geral dos Sistemas (Nichols \& Schwartz, 1998). Revisando a literatura, detecta-se uma profusão de definições acerca do termo "sistema". Entrementes, numa investigação realizada por Jordan (1974), foi visto que existe uma concepção comum a todas elas: um sistema é compreendido como um conjunto de entidades ou elementos unidos por alguma forma de interação ou interdependência que forma um todo integral. Similarmente, Bertalanffy (1975) denotou que os sistemas são complexos de subsistemas colocados em interação, ou seja, um conjunto de elementos que se relacionam entre si e com o meio em busca de um resultado final.

Com essa visão da família como um sistema aberto, isto é, em interação com seu ambiente, diversas formas de atendimento terapêutico foram se definindo. No Brasil percebe-se uma preocupação dentre os formadores em terapia familiar: que a prática desenvolvida esteja adequadamente relacionada com a teoria que a embasa. Um estudo desenvolvido por Eschiletti Prati e Koller (2007) indicou que a formação em terapia familiar visa a uma postura de irreverência teórica, ou seja, conhecer profundamente diversas escolas de modo a construir uma forma pessoal de atender as famílias. Com essa postura há, simultaneamente, uma ampliação de modelos e uma integração entre os mesmos. Assim, pode-se pensar que os terapeutas familiares brasileiros estão capacitados a agir de diferentes formas com os diversos sistemas que buscam atendimento psicoterapêutico.

No presente artigo, algumas possíveis abordagens terapêuticas com pessoas idosas serão apresentadas através de vinhetas de casos prototípicos. Através deles, serão pinçados os temas mais freqüentes no contexto clínico e formas de acionar recursos pessoais que podem influenciar na evolução positiva do caso. São discutidas a terapia individual sistêmica com idosos, a terapia de casal na terceira idade, a terapia familiar com membro idoso(a) e a terapia familiar com o(a) idoso(a) como família extensa. Em cada discussão alguns aspectos terapêuticos são aborda- 
dos, mas isso não quer indicar que estes só apareçam nessa modalidade específica de atendimento. A utilização de casos prototípicos foi escolhida por permitir a construção de possibilidades de intervenção sem indicar um caminho único. Permite, ainda, uma reflexão sobre as inúmeras alternativas terapêuticas que podem ser seguidas.

\section{TERAPIA INDIVIDUAL SISTÊMICA COM IDOSOS}

SITUAÇÃO: Vilma busca terapia por estar se sentindo muito sozinha. Ela tem 72 anos, duas filhas casadas, que moram na mesma cidade que ela. Seu esposo faleceu há 10 anos num acidente, enquanto viajava em função do trabalho. Vilma trabalha há 35 anos como professora e quando pensa em se aposentar sente "um frio na espinha". Nos últimos anos, está trabalhando na biblioteca da escola e o horário de que mais gosta é a Hora do Conto, quando turmas de primeira à quarta série acompanham emocionadas suas narraçôes de histórias infantis. Percebe que muitas de suas amigas já estão aposentadas e bastante envolvidas com problemas de saúde. Não conseguem mais se encontrar como antes. Suas filhas trabalham muito e têm que cuidar de seus filhos e maridos. Vilma procura ocupar seu tempo com leituras e não perde a novela das seis. Sempre foi preocupada com a saúde e quer continuar saudável para não dar mais trabalho para suas filhas e netos.

O processo de envelhecimento, como é exemplificado no caso de Vilma, é permeado por inúmeras transformações em nível biológico, psicológico e social. Por ser a última etapa do ciclo vital, a velhice traduz-se como um período no qual há perdas. No caso, perda do contato com amigas, restrições em função da saúde e redução da jornada de trabalho. No entanto, com freqüência, tais perdas são maximizadas, resultando em práticas sociais discriminatórias contra o idoso e em um senso pessoal de que a vida não tem sentido. Sentimentos de rejeição, solidão, incapacidade, dentre outros, podem eventualmente levar o idoso a apresentar um quadro sintomático de depressão. Muitos são os riscos associados a essa doença que afeta prejudicialmente a qualidade de vida na velhice. Se, por um lado, há danos em aspectos do funcionamento físico, por outro, em nível pessoal, a depressão afeta a qualidade dos relacionamentos sociais e familiares e o bem-estar psicológico do idoso. Estudos revelam que, na velhice, a depressão é o principal fator psicológico associado ao suicídio. Ou seja, ela pode ainda constituir-se em um fator de risco para a própria vida dos idosos (Fortes, 2005).

Pesquisadores que investigaram eventos de vida estressantes indicaram que os que ocorrem com maior freqüência na velhice são: a aposentadoria, a perda de familiares e amigos queridos e o aparecimento ou agravamento de doenças crôni- 
cas (Folkman, Lazarus, Pimley \& Novacek, 1987). No caso descrito, Vilma preocupa-se com a aproximação dessa possibilidade e quer organizar sua vida para prevenir as eventuais perdas. Uma pesquisa realizada por Krause (citada por Fortes, 2005), indica que os eventos estressores atuam nos idosos de forma mais negativa quando afetam os papéis sociais de cônjuge e de progenitor, por despertarem sentimentos de falta de controle no exercício desses papéis. Além disso, especificamente no caso das mulheres, os fatores que representam importantes condições de risco para a depressão são: a maior possibilidade de viuvez, o assumir papéis sociais relacionados ao cuidado, a maior exposição a doenças crônicas, incapacidade funcional, ônus familiar, pobreza e baixo nível educacional (Fortes, 2005; Neri, 2001).

Nessa etapa da vida, a psicoterapia individual torna-se, muitas vezes, fundamental. A cada dia se conhecem melhor os benefícios do tratamento psicológico voltados para essa população. Entretanto, é preocupante o fato de determinados profissionais da área de saúde estarem desinformados e despreparados para lidar com os idosos. Vários deles ainda acreditam que o tratamento psicoterapêutico na velhice é algo impossível de evoluir, alegando que estes pacientes estão próximos do final de vida (Singer, 2001). Nesse prisma,

A terapia psicológica na velhice surge como uma das formas de se promover a saúde do idoso. Através da adoção de uma conduta terapêutica preventiva, alicerçada na ótica da interdisciplinaridade, a psicoterapia pode favorecer um presente e um futuro mais criativos, uma vida mais satisfatória ao sujeito, bem como respostas sobre os vários aspectos do processo de envelhecimento e da velhice (Ferreira \& Falcão, 2006: 426).

Quanto às relaçôes interpessoais na velhice, pelo avanço dos anos de vida, o idoso pode experimentar um decréscimo no número de indivíduos que compõem sua rede social, devido a doenças e mortes de pessoas da mesma idade. Vilma já acompanha o distanciamento das colegas em função de aposentadoria e doença. Diferentes teorias buscam explicações para a redução das relações sociais na velhice. Uma delas é a Teoria da Seletividade Socioemocional, que compreende essa redução com base na perspectiva do idoso sobre o tempo de vida que ainda lhe resta (Carstensen, Pasupathi, Mayr \& Nesselroade, 2000). Os idosos percebem que o seu tempo é curto e limitado e, por isso, investem em relações emocionais significativas. Trata-se, portanto, de um processo motivacional através do qual os idosos selecionam as relações de proximidade afetiva. Neri (2005) sugere que, apesar de serem menos numerosas em sua com- 
posição estrutural, funcionalmente as redes sociais de idosos são mais efetivas e eficazes na promoção de seu bem-estar.

Diferentes funções são atribuídas à rede de suporte social na adultez e na velhice. Algumas das principais relacionam-se: 1) à troca de apoio emocional e de ajuda material; 2) à manutenção e afirmação da identidade social; 3) ao estabelecimento de novas relaçôes sociais; 4) ao reforço da crença das pessoas de que são cuidadas e amadas; e, 5) à possibilidade de criar oportunidades para que as pessoas desenvolvam estratégias de comparação de suas competências e realizações com as de outras pessoas (mecanismos de comparação social). Estas estratégias de comparação social ajudam na manutenção de uma auto-imagem positiva, bem como da auto-estima. Por essa razão, são muito importantes na velhice, principalmente quando é necessário que o idoso se adapte a perdas físicas e sociais (Neri, 2005).

A psicoterapia na velhice deve considerar a percepção do idoso de que o seu tempo é curto e limitado e, por esta razão, estabelecer metas de curto prazo focando o alcance de resultados. Para Sad (2001), a revisão de vida, uma forma de lembrança intencional, estruturada em torno de eventos de transição e aplicada à avaliação de si mesmo e da própria existência, é um instrumento importante para a manutenção da integridade pessoal e do equilíbrio psicológico na meia-idade e na velhice, fases nas quais o senso de finitude torna-se mais saliente. A necessidade de autoconhecimento é uma das responsáveis pela motivação em avaliar a vida, sendo a auto-aceitação uma das resultantes deste processo. A autora, baseada em Jung e Erickson, afirma ainda que a revisão de vida possibilita a recontextualização de significados de experiências passadas e a construção de novos significados de experiências e sentimentos pessoais e sócio-históricos. O caso de Vilma ilustra uma possibilidade de abertura e revisão de vida. Além disso, os contatos estabelecidos com as crianças de $1^{\mathrm{a}}$ a $4^{\mathrm{a}}$ série, através da atividade Hora do Conto, proporciona a busca intencional de recursos pessoais para a vivência saudável dessa fase do ciclo vital.

\section{Terapia de CASAL NA TERCEIRA IDADE}

SitUAÇÃO: Joana e Hélio, casados há 50 anos, buscam atendimento porque estão brigando bastante. Joana afirma que Hélio esquece das combinaçôes que fizeram e Hélio diz que Joana "não dá o braço a torcer". Eles se mudaram há três meses para um apartamento próximo à casa de seu filho único, por solicitação deste. Segundo Joana, o filho acha que o pai está ficando "esclerosado". Ambos estão bastante envolvidos com movimentos de igreja e procuram resolver suas brigas para continuarem a viver bem 
como antes. "Já passou o tempo em que eu podia sair descansada e sabia que Hélio não ia se meter em confusão. Agora tenho que estar sempre com ele. Acho que é isso que está fazendo a gente brigar tanto. Gostamos de ficar juntos, mas o tempo todo é demais!"diz Joana. Hélio também não agüenta a mulher sempre cuidando dele, mas reconhece, rindo, que às vezes “o 'alemão' vem visitar" (referindo-se às perdas de memória e organização características de um possivel diagnóstico de Alzheimer).

$\mathrm{O}$ caso de Joana e Hélio permite o acesso à vivência da velhice em uma família, mais especificamente, um casal. A compreensão da vida através de estágios, com crises vitais e normais de desenvolvimento, permite a visão do próprio casamento como uma estrutura flexível que se remodela ao longo do tempo. No ciclo vital do casal, há pontos críticos, períodos de transição e de crises que levam a modificações nas formas como o casal interage. Tais modificações são importantes para a manutenção de uma relação conjugal satisfatória (Sattler, Eschiletti, de Bem \& Schaefer, 1999). Em qualquer estágio do ciclo vital, o processo terapêutico pode ajudar o casal a pensar, negociar, esclarecer expectativas implícitas, facilitando, desta forma, o desenvolvimento bem-sucedido de todos os membros do sistema familiar. Walsh (2002) apresentou a idéia de que as pessoas precisam de três casamentos ao longo da vida: um amor romântico na adolescência, um relacionamento com responsabilidades compartilhadas no período de criação de filhos e, no final da vida, um casamento no qual os companheiros sejam afetivos e atenciosos, reciprocamente. Para atingir essas três formas de casamento, mais que de novos parceiros, as pessoas precisam alterar seus contratos relacionais.

O ciclo vital do casal tem início em fases anteriores ao casamento uma vez que sofre a influência das famílias de origem dos cônjuges. As diversas fases vivenciadas pelo casal (fase do apaixonar-se, o pânico pré-nupcial, final do período do romance, estabilidade, comprometimento e co-criação) têm desafios que devem ser vencidos. O casal de terceira idade, em sua maioria, vive o período da co-criação, no qual se sentem em condições de devolver ao mundo o que construíram ao longo da vida em comum. Como Hélio e Joana, os casais dessa fase envolvem-se com atividades comunitárias, compartilhando com outras pessoas as experiências adquiridas ao longo da vida. Como em fases anteriores, há o risco de haver investimento demasiado no mundo, deixando pouca energia para investir na relação do casal (Sattler e cols., 1999). Esta fase do ciclo vital é caracterizada por ser o período no qual a afetividade e atenção entre os cônjuges tornam-se o elemento principal da interação conjugal. Joana demonstra essa atenção ao descrever sua preocupação com o possível quadro de Alzheimer de Hélio. É o momento no qual os filhos estão constituindo suas famílias e o casal se vê sozinho diante de desafios pessoais próprios dessa etapa da vida. 
Assuntos que surgem no contexto terapêutico de casais na terceira idade são apresentados por Willi (1993). É neste momento de vida que o marido, e cada vez mais a esposa, se depara com a realidade da aposentadoria. $\mathrm{O}$ tempo ocupado com o trabalho fica disponível para ser despendido com outras atividades e, se não há uma possibilidade de negociação e criação de novas ocupações, o espaço vazio pode gerar um campo de conflito e distanciamento conjugal. Por outro lado, a aposentadoria pode proporcionar um território de intimidade, permitindo ao casal a conquista de atividades conjuntas e prazerosas.

Esta é uma etapa também caracterizada pela morte dos amigos. Depararse com a perda de pessoas próximas e companheiras de vida leva o casal a se defrontar com a finitude da própria existência. A alteração de expectativas de vida e aceitação das suas limitações pode gerar um funcionamento no qual os cônjuges passam a depender mais um do outro. $\mathrm{O}$ casal tende a unir-se de modo que se eleve a dependência mútua. Isto pode ser em parte benéfico e em parte pode criar novos problemas (Willi, 1993). No caso relatado, a aproximação demasiada entre Hélio e Joana gerou uma ampliação do campo de conflito, e a procura por outros espaços de convivência ajudou-os a flexibilizar e buscar a construção de uma nova rotina do casal. Existem situações nas quais um dos membros do casal faz um movimento em direção à independência (assumindo atividades sociais ou investindo em desejos pessoais), e isso desencadeia uma maior dependência por parte do outro cônjuge. Ainda se podem encontrar situaçôes de "guerra de posiçôes", ou seja, um membro do casal quer mostrar-se mais independente do que o outro, gerando uma escalada de poder prejudicial à velhice bem-sucedida.

Podem ocorrer, ainda, situações de isolamento do casal. A convivência com ambientes hostis ou situaçôes que salientam as deficiências normais da velhice pode desencadear um desejo de permanecer em território conhecido, ou seja, em sua casa, com seus familiares e amigos mais íntimos (sem esquecer que essa rede vai diminuindo com a morte dos amigos). Alguns indicadores na literatura relacionam questões de gênero ao tamanho da rede e às relações familiares e de amizade. As mulheres têm mais competências interpessoais, o que torna as relações sociais entre elas qualitativamente melhores do que as entre os homens. Um aspecto particular tem origem no âmbito familiar: as mulheres são apontadas como as principais cuidadoras dos demais membros da família ao longo de suas vidas, o que pode estar associado à manutenção deste papel social ou à possibilidade de receber o cuidado dos familiares como retribuição (Neri, 2005; Paula Couto e cols., 2006). Da mesma forma, Willi 
(1993) afirma que a mulher parece reagir melhor que o homem diante da morte de seu cônjuge.

As redes de apoio informais a idosos (familiares, amigos, vizinhos), principalmente aqueles dependentes, exercem um papel fundamental na manutenção do bem-estar do indivíduo, especialmente quando as redes formais (centros comunitários, hospitais, etc) são escassas ou insatisfatórias. $\mathrm{O}$ casal descrito aproximou-se de seu filho (vindo morar mais próximo deste). No entanto, embora a família seja a fonte primária de apoio social e afetivo ao idoso, as relaçôes de amizade na velhice repercutem de forma especialmente benéfica. Portanto, as amizades funcionam como importante fator de proteção ao idoso, particularmente quando são espontâneas e permitem a troca de experiências e vivências comuns entre pessoas da mesma coorte (Neri, 2005).

O caso vivido por Hélio e Joana também nos faz pensar no desenvolvimento de um possível quadro de doença de Alzheimer (DA). Ao receber a notícia do provável diagnóstico de DA, a família inicia um processo de culpa, por vezes devido à não-valorização das queixas ou sintomas, à irritação e à falta de paciência do familiar para com o portador (Luders \& Storani, 1996). De acordo com Coelho e Diniz (2005), os familiares dos idosos reagem de maneiras diversas diante do diagnóstico de demência, como, por exemplo, ficar chocado ao receber a notícia, ou rejeitar e negar a idéia de que o idoso esteja doente. Muitas dessas reações estão provavelmente ligadas à vivência de perda da pessoa idosa e do lugar que esta ocupa na família. O fato é que o portador da demência progressivamente assume outro modo de ser, embora os traços físicos permaneçam.

A maneira pela qual o sistema familiar e seus membros lidam com a situação vivenciada pelos idosos com demência entrelaça-se às relações interpessoais, transgeracionais e de parentesco desenvolvidas ao longo dos anos. Segundo Yuaso (2002), a forma como a família e o cuidador avaliam e manejam a situação de cuidado depende de alguns fatores, a saber: a) a disponibilidade de redes de apoio formal e informal; b) as estratégias de enfrentamento peculiar a cada indivíduo e a cada família; c) o significado de cuidar para os envolvidos; d) o modo como as pessoas manejam o estresse e como buscam conforto emocional; e, e) os fatores de personalidade e o relacionamento anterior à doença entre os membros.

Por fim, laços sociais têm sido identificados como redutores do risco de depressão entre idosos e como promotores de autoconfiança (García, Banegas, Pérez-Regadera, Cabrera, \& Rodriguéz-Artalejo, 2005). O suporte social está ainda associado a uma melhor habilidade cognitiva, ao bem-estar e à satisfação com a vida em idosos (Bourque, Pushkar, Bonneville \& Béland, 2005). 


\section{Terapia FAMILIAR COM MEMBRO IDOSO}

SitUAÇÃo: Uma familia é encaminhada para atendimento pela professora de uma escola que conta que sua aluna diz que "é burra, sempre foi burra e não vai mudar". É solicitado que todos os que moram na casa compareçam à primeira sessão. Aparecem: a mãe, o pai, a filha de nove anos que está repetindo a segunda série pela terceira vez, seu irmão de cinco anos e a avó materna, que sempre morou com eles. A terapeuta começou a explorar a escolaridade de cada membro da familia e percebeu que apenas a mäe conseguiu completar a quinta série, com muitas dificuldades. A avó diz que sempre quis estudar, mas seu pai não deixou porque ela era "muito burra". O pai freqüentou a escola até a segunda série e parou "porque ganhava mais trabalhando do que estudando". Quem ajuda nos temas é a avó que, mesmo sem nunca ter freqüentado escola regular, consegue "juntar as letras e formar palavras". A sensação da terapeuta é que essa família não está preparada para se sentir inteligente, afinal "todos são burros e se dão melhor no trabalho braçal. A escola é perda de tempo".

Através da inclusão de membros idosos na terapia de uma família abre-se uma porta de acesso a antigos mitos e legados familiares. $\mathrm{O}$ mito compõe a história da família, forma uma rede de eventos, papéis, conteúdos e relaçôes que destacam elementos e indicam formas "possíveis" de narração da história. Num mito co-existem elementos de realidade e fantasia que, juntos, contribuem para a construção de uma narrativa adequada para suprir a necessidade de dar um sentido ao que acontece de forma ambígua ou casual na história familiar. Os mitos são tanto mais ameaçadores (e, portanto, menos questionados) quanto menos se possa reconhecer nos acontecimentos uma intencionalidade (Andolfi \& Ângelo, 1989). Neste caso, todos se sentem incompetentes com relação à vivência escolar (desde a geração da avó, não há sucesso na escola).

O mito é constituído em qualquer relação, pois sempre existe uma margem de ambigüidade, de algo não expresso diretamente no encontro. Os não ditos ou implícitos são territórios vagos, para serem preenchidos por mitos e regras inconscientes. Estas últimas se referem às atitudes que são tomadas nas relações pessoais mais próximas sem nunca terem sido conversadas. Apenas se age de forma complementar sem nunca combinar claramente como cada um deve agir. Portanto, mitos e regras são dois termos que se misturam e se sobrepõem. Mitos, entretanto, são de mais difícil questionamento e regras podem (ou não) ser negociadas e flexibilizadas. O desenvolvimento do mito familiar parece ter sua base em problemas não resolvidos de perda, separação, abandono, entre outros. Neste caso, a impossibilidade de ser bem-sucedido nos estudos está relacionada a uma vida de fracassos e sofrimentos, na qual o trabalho braçal é a única oportunidade de so- 
brevivência. A transferência intergeracional e transgeracional dos mitos determina o surgimento e evolução dos papéis comuns e esperados em cada sistema. Para a criação de um mito familiar são necessárias três gerações (Andolfi \& Ângelo, 1989; Prado, 1996). Famílias de origem "delegam” funçôes específicas para cada membro durante a composição de novas famílias. Quando essa "missão" é transferida para a geração seguinte, há um distanciamento entre os motivos que geraram a delegação inicial e o membro desta geração. Assim, há uma repetição de legados que, por estarem envolvidos em mitos e desconectados do contexto inicial, não são questionados.

O mito familiar é uma crença compartilhada e integrada ao cotidiano familiar, referindo-se a cada membro da família, definindo as posições recíprocas do sistema familiar nuclear e extenso. Ele oferece um modelo prescritivo e valorativo de leitura da realidade. Os mitos familiares, provenientes do entrelaçamento dos vários mitos individuais, tende a não se alterar pela cumplicidade, mais ou menos inconsciente, de cada indivíduo. O mito é a chave para a leitura das interaçõos da família. Através dele a realidade e as diversas experiências cotidianas são interpretadas. $\mathrm{O}$ mito familiar entrelaça-se com os acontecimentos do ciclo evolutivo interferindo no desenvolvimento e, portanto, alterando-se constantemente. As "crises vitais" do desenvolvimento são momentos importantes para a revisão, manutenção e/ou rompimento dos mitos familiares.

Existem poucos estudos sobre a influência da família de origem na vida do novo casal. Loriedo e Strom (2002) descrevem três estudos que encontram resultados semelhantes: a família de origem da mulher exerce maior influência no grau de satisfação da relação conjugal do que a do homem. A presença de conflitos na família de origem da mulher dificulta negociaçōes no novo casal e aumenta o grau de insatisfação do parceiro. $\mathrm{O}$ mesmo não foi identificado frente à presença de conflitos na família do homem. Explicam esse dado a partir das questóes de gênero: é esperado que as mulheres se responsabilizem pela arquitetura das relações afetivas na família. Sendo assim, acionam-se primeiramente os recursos desenvolvidos na família de origem da esposa.

Há uma expectativa cultural de que o casamento é um momento de independência do novo casal de suas famílias de origem. Entretanto, é possível encontrar inúmeras famílias trigeracionais, ou seja, um casal com ou sem filhos e suas famílias de origem (comumente a mãe de um dos cônjuges) morando juntos. Nessas configurações familiares, os legados se amplificam. Em algumas situações essa é a única alternativa para a sobrevivência financeira desse novo sistema, em outras essa organização se dá em função de mitos familiares que não podem ser questionados. No caso descrito, a moradia conjunta se dá em função de dificulda- 
des financeiras, mas a presença da trigeração afeta substancialmente o desenvolvimento do sistema familiar (afinal, a avó é a responsável pela educação dos netos).

A família trigeracional acaba por apresentar características especiais. Em alguns momentos, a participação dos pais dos cônjuges no contexto terapêutico pode ser de extrema valia. Porém essa aproximação precisa ser bem avaliada. Quando as questôes trazidas para atendimento envolvem, direta ou indiretamente, as interações com as famílias de origem (intromissões e conflitos), sessões conjuntas podem ser fundamentais para o bom desenvolvimento da terapia. Porém, quando esse conflito é entre o casal, o afastamento das famílias de origem pode ser uma poderosa ferramenta para definir os limites do novo sistema conjugal. Outro caso para se avaliar o contato com a terceira geração é quando a família procura respostas explicativas para as dificuldades atuais. A preocupação com o passado e com a história familiar pode desencadear uma conversa entre as geraçôes para esclarecer mitos e legados que não haviam sido questionados até então (Loriedo \& Strom, 2002).

Em qualquer família, as pessoas estão envolvidas em lealdades interpessoais. Ou seja, sofrem a influência de expectativas grupais estruturadas, nas quais todos os membros estão comprometidos. As famílias de origem de ambos os cônjuges, com suas estruturas de lealdade, podem reforçar ou solucionar problemas que o casal em formação pode estar vivenciando. É importante estar atento a dois aspectos: avaliar se os cônjuges aceitam a lealdade dos parceiros com suas famílias de origem, e se não há a transferência de conflitos não resolvidos de um núcleo familiar para outro. Os "sogros" e "sogras" envolvem-se em conflitos de lealdades através de exigências (implícitas ou não) aos membros do novo casal, ou são alvos de discórdia entre os cônjuges, quando há uma transferência de tensōes (Nichols, 1990).

\section{TeraPia FAMILIAR COM O IDOSO COMO FAMÍlIA EXTENSA}

SituAÇão: Paulo e Salete estão completando o décimo quinto ano de casamento. Têm um filho de 14 anos e tentam engravidar novamente há sete anos. Ambos são filhos unicos e gostariam de que seu filho pudesse aprender a dividir com pelo menos um irmão, experiência que ambos não tiveram. Salete já sofreu três abortos espontâneos e eles têm a sensação de que estão sendo castigados e não conseguirão mais ter filhos. Atualmente, Salete está grávida de três meses e tem muito medo de perder mais esse filho. Por estarem muito ansiosos, buscam terapia. A terapeuta convida os avós maternos e paternos para comparecerem a um atendimento (como consultores). O objetivo é o de criar uma rede de pessoas que possam tranqüilizar Salete. Durante o atendimento à família extensa, a avó paterna começa a chorar. A avó conta que, quando ouviu 
Salete dizer que estava se sentindo castigada, ela se sentiu o próprio carrasco. Logo após o nascimento de Paulo ela forçou um aborto, pois considerava que ninguém teria condiçôes de criar duas crianças. Ela nunca falou sobre isso a ninguém, mas sempre se arrependeu por sua atitude.

O casamento, um dos momentos bastante estudados no ciclo vital, é uma ruptura e uma integração de sistemas. Os filhos não deixam de fazer parte de suas famílias de origem e constituem um novo sistema, e às famílias de origem se adiciona o cônjuge. Loriedo e Strom (2002) enfatizam que ao se casar com uma pessoa se casa com sua família. Sendo assim, para compreender a dinâmica de um casal, um recurso que pode ser utilizado pelo terapeuta é convidar as famílias de origem para um encontro ou para uma série de atendimentos. Compreender as interações entre as gerações proporciona uma visão mais integrada e rica dos impasses, mitos e legados que compóem a dinâmica familiar em atendimento. $\mathrm{O}$ convite aos pais de Salete e Paulo permitiu que um segredo viesse à tona e possibilitou a revisão do sentimento de estar sendo castigada (vivido intensamente por Salete).

Os mitos referem-se a situações que não podem ser lembradas ou faladas, fazendo com que a família construa um conluio sobre não tocar em assuntos que se referem a um segredo. A conversa aberta com membros mais idosos da família pode permitir uma melhor compreensão de algumas regras e atitudes que são guias de conduta da família e não são questionadas. Mesmo conversando sobre aspectos delicados da história familiar, a re-narração do passado pode servir como um momento de re-elaboração e re-construção do mito familiar. $\mathrm{O}$ acesso a essa história permite um questionamento e até um rompimento de legados disfuncionais inconscientes que podem estar dificultando as interações da família em terapia.

Os segredos familiares geram distorções de informações e evitação dos assuntos que podem ameaçar o funcionamento do sistema. Os que sabem sobre a existência do segredo acabam se angustiando por não poderem falar sobre as ansiedades referentes a esse assunto. Os que estão de fora se sentem inseguros e confusos quando percebem a existência de áreas das quais não se pode falar. Papp (1994) enfatiza que muitos segredos surgem para tentar proteger os outros membros do sistema, entretanto acabam por distanciar as pessoas e fragilizar a confiança entre elas. Quando crescem em um ambiente com segredos, as crianças aprendem que enganar é possível e que o outro é incapaz de lidar com questóes sérias. Paulo cresceu sem saber que teria um irmão. Possivelmente a sensação de perda, dúvida e receio quanto à possibilidade de cuidar de dois filhos foi transmitida de forma velada para ele. 
Há uma linha tênue entre a privacidade e o segredo. O terapeuta deve estar atento se a informação sigilosa é relevante para o funcionamento do restante do sistema - esse é o aspecto que define se as informaçôes devem ser partilhadas ou não. A relevância do sintoma e a necessidade ou não de revelação é avaliada através dos seguintes aspectos: interferência no funcionamento dos membros (construção de sintomas); impedimento de comunicação direta e franca (vários pontos da história familiar não podem ser contados porque podem desvelar o segredo); avaliação dos efeitos da revelação não planejada do mesmo (nível de devastação da estrutura familiar); avaliação de quem sabe e o quanto sabe; avaliação sobre quem deve saber sobre o segredo (desta forma se mantém a privacidade necessária nos subsistemas); e exploração dos efeitos de uma revelação planejada (Papp, 1994).

Um casamento pode estar paralisado ou sintomático em função de memórias e lembranças que se tem das famílias de origem. A história que é construída com as famílias de origem define as expectativas que temos com relação ao casamento atual e à forma de se relacionar com amigos e parentes por afinidade. É difícil uma ruptura total com o sistema de origem, devido à transmissão transgeracional de relações e formas de interaçôes. O importante é manter-se diferenciado do sistema de origem. Diferenciar-se não é separar-se, mas alcançar uma identidade autônoma, reconhecendo semelhanças e diferenças com relação à família de origem. Os pais podem contribuir para essa diferenciação se apontam, nas atitudes habituais da família, para um momento no qual o filho terá responsabilidades fora da mesma (Nichols, 1990). Paulo e Salete buscavam sua diferenciação ao tentarem ter dois filhos. Essa decisão pode ter sido entendida como ruptura por parte dos pais de Paulo por romperem com uma crença forte na família (não é possível criar dois filhos).

Recomenda-se que o convite para a participação esporádica de um membro da família de origem no processo terapêutico seja em tom de auxílio. Os membros devem ser convidados como uma ajuda ao terapeuta, acreditando que sua experiência, sua competência e seu patrimônio cultural são excelentes recursos para a consultoria do terapeuta e da família (Loriedo \& Strom, 2002). Os idosos possuem uma perspectiva mais ampla do desenvolvimento da família e podem apresentar as peças da história que faltam para a compreensão dos impasses e angústias atuais.

$\mathrm{O}$ acesso a essa riqueza pode permitir uma re-narração da história da família. Recursos do sistema, outrora esquecidos, podem ser acessados. Uma situação pode assumir um significado completamente novo, até oposto. O próprio idoso pode perceber sua importância e auxiliar o novo sistema a construir outra forma de interação e construção de uma forma de convivência mais positiva. 


\section{CONSIDERAÇÓES FINAIS}

As possibilidades terapêuticas com a população idosa não se encerram nesses quatro exemplos. Aqui somente foi possível dar uma breve noção que indica a riqueza que o trabalho com essa população pode apresentar. Apesar de problemas e dificuldades característicos da velhice, o terapeuta pode conectar-se com os aspectos saudáveis e "preciosos" da pessoa que vivencia as últimas fases do ciclo de vida.

Entretanto, é fundamental estar atento a algumas características que perpassam qualquer trabalho com essa faixa etária. Estas podem ser encaradas como impedimentos, desafios ou possibilidades. $\mathrm{O}$ conhecimento das mesmas e a abertura para o trabalho levando-as em consideração são muitas vezes a peça chave para o sucesso da intervenção terapêutica e da promoção de uma velhice bem-sucedida.

Salientam-se aspectos referentes à noção de tempo apresentada pelos idosos. A idéia de "finitude" é lembrada sempre que um amigo falece ou quando se dão conta que muitas vezes não podem fazer o que faziam antes. Eizirik e Kapczinski (1993) afirmaram que pacientes que buscam a terapia apresentando dificuldade de ajustamento a essa nova fase, uma reação de luto não-resolvida ou um distúrbio de estresse pós-traumático, podem beneficiar-se com uma psicoterapia dinâmica breve. A reconstrução da história de vida do paciente pode ser um grande auxílio se o foco estiver na "descoberta" de recursos pessoais e na valorização do que foi construído ao longo da sua vida. Quando o idoso, seja em atendimento individual ou familiar, reconhece em si recursos que podem melhorar a situação do seu sistema familiar, aciona e conecta-se com os aspectos que permitem uma velhice em contato com aqueles que o amam.

Ao definir os objetivos terapêuticos é importante atentar para que estes sejam realistas e operativos (Eizirik \& Kapczinski, 1993). Levando em consideração o quadro clínico do paciente, de forma geral, os objetivos devem contemplar as seguintes áreas: desenvolvimento da capacidade de falar sobre si e seus problemas, melhora na auto-estima, manejo dos sintomas e aumento na capacidade de utilizar recursos próprios, familiares e da comunidade.

No momento em que um objetivo é estabelecido, o terapeuta assume a responsabilidade de mantê-lo no centro das intervenções clínicas. O paciente atinge suas metas, seguindo intervenções diretas e breves construídas no processo terapêutico. Essas intervenções, baseadas na perspectiva sistêmica, podem acionar os recursos presentes na rede social (amigos, familiares, agentes de saúde e grupos de convivência) a que pertencem. Todavia, é válido ressaltar que Checkland (1994) apontou para a inexistência de um corpo teórico consolidado, seja na forma de uma teoria geral ou como um conjunto de noções e princípios básicos de uma epistemologia ou 
linguagem sistêmica geral. Considerou, portanto, que uma das vertentes do movimento sistêmico é a ausência de uma perspectiva unificada, muito embora haja, em algumas esferas, um compartilhamento de idéias semelhantes ou aproximadas. Assim, não se pode falar sobre o pensamento sistêmico como algo único, mas sim sobre versões do pensamento sistêmico. "A teoria dos sistemas não é na verdade uma doutrina coerente, padronizada, mas é mais uma maneira de pensar, e há muitas variaçôes sobre o tema sistêmico" (Nichols \& Schwartz, 1998: 87).

Um foco terapêutico importante é a resiliência, construto que enfatiza os aspectos sadios e de sucesso (Rutter, 1987). O trabalho focado na resiliência deve buscar identificar e implementar os processos que possibilitam que as pessoas lidem de modo mais eficiente com situações de crise ou estresse e, além disso, saiam fortalecidas das mesmas (Walsh, 1998). Nas pesquisas sobre envelhecimento bem-sucedido, o equilíbrio entre as limitações e as potencialidades do indivíduo desempenha um papel importante na busca do envelhecer bem. Ao balancear as perdas e os ganhos decorrentes da idade, o idoso tem a oportunidade de desenvolver formas positivas de lidar, cada um com um grau de auto-eficácia, com as perdas inevitáveis do envelhecimento (Neri, 2003). A manutenção do bem-estar em situaçôes adversas também está implicada com o processo de resiliência (Ryff, Singer, Love \& Essex, 1998). Desta forma, fatores que podem ser estimulados para a melhora ou manutenção do bem-estar na velhice incluem: saúde física, saúde percebida, satisfação com a família, situação econômica e psicológica, capacidade de iniciar e de manter contatos sociais e avaliação que o idoso faz de sua situação atual (Neri, 2003).

Enfim, a terapia na velhice pode ser um campo propício para a valorização da sabedoria e da história de vida da pessoa que vive esse momento específico do ciclo vital. O movimento de perceber que os velhos têm recursos (hoje e ao longo de sua história pessoal) fortalece vínculos com sua família, seus amigos e com eles mesmos. É, portanto, uma ferramenta útil na construção e promoção de um envelhecimento saudável.

\section{REFERÊNCIAS BIBLIOGRÁFICAS}

Andolfi, M. \& Ângelo, C. (1989). Tempo e mito em psicoterapia familiar. Porto Alegre: Artes Médicas.

Bertalanffy, L. V. (1975). Teoria geral dos sistemas. Petrópolis: Vozes.

Bourque, P.; Pushkar, D.; Bonneville, L. \& Béland, F. (2005). Contextual effects on life satisfaction of older men and women. Canadian Journal on Aging, 24, 1, 31-44.

Carstensen, L. L.; Pasupathi, M.; Mayr, U. \& Nesselroade, J. R. (2000). Emotional experience in everyday life across the adult lifespan. Journal of Personality and Social Psychology, 79, 4, 644-655. 
Checkland, P. (1994). Varieties of systems thinking: the case of soft systems methodology. Systems Dynamics Review, 10, 189-197.

Coelho, V. L. \& Diniz, G. (2005). Da solidão à solidariedade: grupos de familiares de idosos com demências. In: Féres-Carneiro, T. (org.). Casal e família: efeitos da contemporaneidade (pp. 177-199). Rio de Janeiro: Editora da PUC-Rio.

Eizirik, C. \& Kapczinski, F. (1993). Psicoterapia na velhice. In Cordioli, A. V. (ed.). Psicoterapias: abordagens atuais (pp. 420- 432). Porto Alegre: Artes Médicas.

Eschiletti Prati, L. \& Koller, S. H. (2007). Formação em terapia familiar: desafio dos formadores. Pensando Famílias, 11, 1, 115-126.

Ferreira, D. M. L. \& Falcão, D. V. (2006). A velhice e a psicoterapia na perspectiva de pessoas idosas. In: Falcão, D. V. \& Dias, C. B. (eds.). Maturidade e velhice: pesquisas e intervenções psicológicas (pp. 423-443). São Paulo: Casa do Psicólogo.

Folkman, S.; Lazarus, R. S.; Pimley, S. \& Novacek, J. (1987). Age differences in stress and coping processes. Psychology and Aging, 2, 2, 171-184.

Fortes, A. C. G. (2005). Eventos de vida estressantes, estratégias de enfrentamento, senso de auto-eficácia e estados depressivos em idosos residentes na comunidade: dados do PENSA. Dissertação de Mestrado, Universidade Estadual de Campinas, Faculdade de Educação, Programa de Pós-Graduação em Gerontologia, Campinas, São Paulo.

García, E. L.; Banegas, J. R.; Pérez-Regadera, A. G.; Cabrera, R. H. \& Rodriguéz-Artalejo, F. (2005). Social network and health-related quality of life in older adults: a populationbased study in Spain. Quality of Life Research, 14, 2, 511-520.

Jordan, N. (1974). Temas de psicología especulativa. Buenos Aires: Editorial Troquel.

Knopoff, R.; Santagostino, L. \& Zarebski, G. (2004). Resiliencia y envejecimiento. In Melillo, A.; Ojeda, E. N. S. \& Rodríguez, D. (eds.). Resiliencia y subjetividad: los ciclos de vida (pp. 214-228). Buenos Aires: Paidós.

Loriedo, C. \& Strom, P. (2002). Os processos de transmissão transgeracional nos casais e o tratamento das problemáticas ligadas às famílias de origem. In: Andolfi, M. (ed.). A crise do casal: uma perspectiva sistêmico-relacional (pp. 123-138). Porto Alegre: Artmed.

Luders, S. L. A. \& Storani, M. S. B. (1996). Demência: impacto para a família e a sociedade. In: Papaléo Netto, M. (org.). Gerontologia (pp. 147-157). São Paulo: Atheneu.

Neri, A. L. (2001). Paradigmas contemporâneos sobre o desenvolvimento humano em psicologia e em sociologia. In Neri, A. L. (ed.). Desenvolvimento e envelhecimento: perspectivas biológicas, psicológicas e sociológicas (pp. 11-37). Campinas: Papirus.

. (2003). Qualidade de vida no adulto maduro: interpretaçôes teóricas e evidências de pesquisa. In: Neri, A. L. (ed.). Qualidade de vida e idade madura (pp. 9-55). Campinas: Papirus.

. (2005). Palavras-chave em gerontologia. Campinas: Alínea. 
Nichols, M. P. (1990). O poder da família: a dinâmica das relações familiares. São Paulo: Saraiva.

Nichols, M. P. \& Schwartz, R. C. (1998). Terapia familiar: conceitos e métodos. Porto Alegre: Artes Médicas.

Papp, P. (1994). O caruncho no broto: segredos entre pais e filhos. In: Imber-Black, E. (org.). Os segredos na família e na terapia familiar (pp. 76-93). Porto Alegre: Artes Médicas.

Paula Couto, M. C. P.; Koller, S. H. \& Novo, R. F. (2006). Resiliência no envelhecimento: risco e proteção. In Falcão, D. V. \& Dias, C. B. (eds.). Maturidade e velhice: pesquisas e intervenções psicológicas (pp. 315-338). São Paulo: Casa do Psicólogo.

Prado, L. C. (1996). Metáforas, segredos e mitos ao longo do ciclo vital: uma reflexão clínica. In Prado, L. C. (ed.). Famílias e terapeutas: construindo caminhos (pp. 199-212). Porto Alegre: Artes Médicas.

Rutter, M. (1987). Psychosocial resilience and protective mechanisms. American Journal of Orthopsychiatric, 57, 3, 316-331.

Ryff C. D.; Singer, B.; Love, G. D. \& Essex, M. J. (1998). Resilience in adulthood and later life: defining features and dynamic processes. In: Lomranz, J. (ed.). Handbook of aging and mental health: an integrative approach (pp. 69-96). New York: Plenum.

Sad, I. (2001). Revisão de vida, autoconhecimento e auto-aceitação: tarefas da maturidade. In: Neri, A. L. (ed.). Maturidade e velhice: trajetórias individuais e sócio-culturais (pp. 53-69). Campinas: Papirus.

Sattler, M. K., Eschiletti, L. L., de Bem, L. A. \& Schaefer, M. (1999). O ciclo de vida do casal. Pensando Famílias, 1, 41-47.

Seligman, M. E. P. \& Csikszentmihalyi, M. (2000). Positive psychology: an introduction. American Psychologist, 55, 5-14.

Singer, D. (2001). Terceira idade merece atenção. Revista Viver Psicologia, 104, X, 32-33. Walsh, F. (1998). Strengthening family resilience. London: The Guilford Press.

. (2002). Casais saudáveis e casais disfuncionais: qual a diferença? In: Andolfi, M. (ed.). A crise do casal: uma perspectiva sistêmico-relacional (pp. 13-28). Porto Alegre: Artmed.

Willi, J. (1993). La pareja humana: relación y conflicto. Buenos Aires: Morata.

Yuaso, D. R. (2002). Cuidar de cuidadores: resultados de um programa de treinamento realizado em domicílio. In: Neri, A. L. (org.). Cuidar de idosos no contexto da família: questôes psicológicas e sociais (pp. 165-201). São Paulo: Alínea.

Recebido em 11 de setembro de 2007 Aceito para publicação em 5 de fevereiro de 2008 